\title{
Creating Engineering Design Cases from Student Work Term and Design Project Reports
}

\author{
Oscar Nespoli, Andrea Hagedorn, Colin Campbell and Stephan Lambert
}

\begin{abstract}
Engineering design case studies were developed from student co-op work term reports and $4^{\text {th }}$ year student design project reports. This paper describes the process used to develop the case studies, and based on the authors' early experiences, makes recommendations for generating and developing cases from student reports.
\end{abstract}

Index Terms - Cases, case method, engineering design, student reports

\section{INTRODUCTION}

$\mathrm{T}$ he National Sciences and Engineering Research Council (NSERC) and General Motors of Canada Limited (GMCL), support a program to enhance engineering design education at the University of Waterloo (UW). The NSERC-GMCL Chair in Collaborative Design (Chair) has been established to develop, implement and promote the use of engineering design cases across the Faculty of Engineering curriculum. The prime innovation of this program is to use student co-op work term reports as case source material, and a group within the Chair, Waterloo Cases in Design Engineering (WCDE), is in place to establish and develop this activity.

The University of Waterloo is a co-operative engineering school where students are required to gain practical engineering experience between each academic term. Over one thousand (1000) work term reports, capturing this experience, are submitted at the end of each term of four (4) months. Additionally, $4^{\text {th }}$ year student reports, or so called capstone design projects, are also candidate case sources. Both represent sustainable sources of case material that can be

Manuscript received June 16, 2008. This work was supported in part by the National Sciences and Engineering Research Council (NSERC), and General Motors of Canada Limited (GMCL).

O. G. Nespoli is with the Waterloo Cases in Design Engineering (WCDE) group, Department of Mechanical and Mechatronics Engineering, University of Waterloo, Waterloo, Ontario, Canada, N2L 3G1 (phone: 519-888-4420; fax 519-885-5862; e-mail: oscar@ design.uwaterloo.ca).

A. Hagedorn is with the Waterloo Cases in Design Engineering (WCDE) group, Department of Mechanical and Mechatronics Engineering, University of Waterloo, Waterloo, Ontario, Canada, N2L 3G1 (e-mail: andrea@design.uwaterloo.ca).

C. G. W. A. Campbell is with the Waterloo Cases in Design Engineering (WCDE) group, Department of Mechanical and Mechatronics Engineering, University of Waterloo, Waterloo, Ontario, Canada, N2L 3G1 (e-mail: campbell@design.uwaterloo.ca ).

S. B. Lambert is the NSERC-GMCL Chair in Collaborative Design and leads the Waterloo Cases in Design Engineering (WCDE) group, Department of Mechanical and Mechatronics Engineering, University of Waterloo, Waterloo, Ontario, Canada, N2L 3G1 (e-mail: steve@design.uwaterloo.ca ). tapped, developed and published for future educational use at UW or at other educational institutions.

A group has been established to develop student reports into engineering design cases and is also active in obtaining engineering design case materials from industry partners. The group also offers graduate level design education courses for a new Master of Engineering (MEng) Design Certificate specialization. As students participating in this program are required to capture their design experiences in the form of engineering design cases, this also represents a sustainable source of design case material.

The purpose of this paper is to describe the authors' early experiences in developing cases from student reports, and to present lessons-learned and recommendations for future conversions of student reports into useful pedagogical mechanisms for the learning of engineering design methodology and practice.

\section{CASES}

Cases, and more specifically the case method, are used extensively and successfully in business, law and medical education to impart practice-based knowledge in a classroom setting.

A very useful summary of the benefits of cases for business education was published in 1940, and reprinted with permission as a case [1].

Cases are accounts of real experiences. When properly implemented, they promote active rather than passive learning.

Cases incorporate what Ref [2] describes as InteractiveEngagement (IE) strategies. This is to say cases "promote conceptual understanding through ....activities which yield immediate feedback through discussion with peers and/or instructors".

Cases increase course effectiveness well beyond that obtained using traditional lecture and laboratory style methods. The literature also suggests that cases accommodate different student learning styles [3].

\section{ENGINEERING DESIGN CASES}

Engineering design cases developed at UW show promise as tools for teaching engineering design [4].

The development of design cases for use at UW is most concerned about teaching best design principles and practices in both typical and unique situations.

The aspects of engineering design education that is perhaps of greatest interest are: 
- problem finding as opposed to problem solving, and

- $\quad$ ill-defined problems as opposed to well-defined ones [6].

Cases offer flexibility in handling these critically important characteristics of the Engineering design process.

The Ivey School of Business at the University of Western Ontario (UWO) is one of the largest publishers of business cases in the world. They assert that publishing a case, complete with approval from the case source (student or industry), is a very important step in case development [7]. Publishing a case lends credibility and authenticity to the case, which promotes maximum engagement by the students during case use.

\section{CAse Development Process}

The case development process being developed and evaluated at the University of Waterloo incorporates important elements from [7], with variations specific to the needs of engineering design cases at UW. The process is shown in Table I.

TABLE I

Case Development Process at UW

\begin{tabular}{ccl}
\hline \hline Step & Description & \multicolumn{1}{c}{ Comment } \\
\hline 1 & $\begin{array}{c}\text { Identify Real Situation (source) } \\
\text { Identify Curriculum Need (receptor) }\end{array}$ & \\
2 & Develop Case Plan & \\
3 & Provisional Release & $\begin{array}{l}\text { Source support for plan } \\
\text { Instructor intent to use }\end{array}$ \\
4 & Develop Case & \\
5 & Release Case & $\begin{array}{l}\text { Source approval to use } \\
\text { Author(s) approval to use } \\
\text { Chair approval to use }\end{array}$ \\
6 & Develop Teaching Note & \\
7 & Case use & For UW use only \\
8 & Revise Case & $\begin{array}{l}\text { Case revisions } \\
\text { Teaching Note revisions } \\
\text { For UW use and } \\
\text { external distribution }\end{array}$ \\
10 & Re-release & Remove from distribution \\
\hline
\end{tabular}

Interestingly, the development of a case is itself a design activity. The process begins by identifying opportunities where available case sources match currently curriculum needs.

The structure of the Chair includes a team of Design Champions from each of the Faculty of Engineering departments. They help in identifying, listing and communicating case needs to the Chair on a recurring basis.

When students submit their work reports they are given permission forms that explain the program to them, and ask them to allow their work term reports to be converted to a case if selected by the WCDE. Submitted reports are scanned and catalogued in a searchable database for future use. For capstone design project reports, the process is similar.

For promising student reports, a basic case plan is developed that summarizes possible case outcomes in just enough detail to permit review by all of the stakeholders (sources and instructors) and obtain their approval to proceed. The elements of the case plan are summarized in Table II below.

TABLE II

Case Plan Elements [7]

\begin{tabular}{cc}
\hline \hline No & Description \\
\hline 1 & Case Title \\
2 & Introduction \\
3 & Teaching Objectives Statement \\
4 & Organization of Case by Subtitles \\
5 & Data Requirements List \\
6 & Time Plan
\end{tabular}

Once agreement is obtained to proceed, the case can be written in full. This is typically an intensive effort on the part of the case developer, and usually requires periodic interaction with the case source contact. This process is much easier here since most of the case material, figures and text are already prepared in the form of the original report. Conversion to a case is fundamentally a process of reformatting and editing. Even so, adhering to the case development schedule usually depends on the level of responsiveness of this contact. Authorship of the case would typically be the original authors (s) of the report followed by the case developer. Once the case is complete it can be presented for release.

\section{CONVERTing a Student Co-OP WORK TERm Report INTO A DESIGN CASE}

Shortly after the program was internally announced, we received two (2) work term reports from a student who recognized the educational and promotional potential associated with developing a case. The work term reports captured his experience during two consecutive work terms at a local electronic device manufacturer. One was selected for conversion to a case. The student was tasked to re-design existing manufacturing test equipment to accommodate increased complexity of circuit card assemblies and increased production volumes. The work performed led to a design that was deemed patentable [8].

After a case plan was generated, we met with the student and obtained additional implicit information on aspects of the report, including nuances regarding the nature of the problem to be solved, and details regarding the design. This included operator feedback on ergonomics, details on how the patentable idea came about, and details regarding the design that were not discussed at length in the report.

A case was developed that focused on both the approach the student took to the design challenge, and the quality of the design solution. The educational value of the work was based on the fact that a conflict in design requirements was resolved elegantly, and that it was resolved in a methodical fashion. The case was drafted into several modules to reflect these aspects as outlined in Table III. 
After student review and approval, the case was submitted to the company for approval. While we have received initial feedback suggesting the case will likely be approved, the process has been protracted. We have found it important to take this potential schedule risk into account when developing cases during the time the case plan is generated and at provisional release.

TABLE III WCDE-00017 POWER-UP CLIP

\begin{tabular}{|c|c|c|}
\hline Module & Title & Comment \\
\hline 01 & Case & $\begin{array}{l}\text { Includes } \\
\text { - Introduction } \\
\text { - Company description } \\
\text { - Current Power-Up Clip design } \\
\text { - Task with schedule and cost } \\
\text { constraints } \\
\text { - Exhibits }\end{array}$ \\
\hline 02 & Need Analysis & $\begin{array}{l}\text { Includes } \\
\text { - Problem definition } \\
\text { - Initial production testing and } \\
\text { data } \\
\text { - Project plan }\end{array}$ \\
\hline 03 & Conceptual Design & $\begin{array}{l}\text { Includes } \\
\text { - Analysis of existing design } \\
\text { - Conflict between operator } \\
\text { ergonomics and clip function } \\
\text { - Analysis, assessment of } \\
\text { alternatives and description of } \\
\text { proposed design improvements }\end{array}$ \\
\hline 04 & $\begin{array}{l}\text { Detailed Design and } \\
\text { Prototype }\end{array}$ & $\begin{array}{l}\text { Includes } \\
\text { - Solid model of preliminary } \\
\text { design } \\
\text { - Test results using new design } \\
\text { showing marked improvement } \\
\text { in test performance } \\
\text { - Summary of project plan } \\
\text { performance for budget and } \\
\text { schedule }\end{array}$ \\
\hline
\end{tabular}

\section{CONVERTING A CAPSTONE StUdent Report InTO A DESIGN CASE}

The process developed for the conversion of work term reports to design cases has also been applied to a fourth year design project report. This represents an important alternate source of case material which is available to all Universities. One of the first student reports converted to a design case [9] was a $4^{\text {th }}$ year capstone design project entitled Design of a Foot Brace For Long Distance Running [10].

The student was motivated to design a foot brace as a result of a knee injury he suffered playing soccer. The injury to his knee, and the nerve that passes through the knee down to the foot, resulted in a condition commonly referred to as foot drop. The long term consequence of this injury was that the student could no longer control the lifting, or the everting (twisting outwards) of his foot. While this condition is not normally painful, it interferes with walking, makes running impractical and playing soccer impossible.

The student was successful in designing a brace that was a novel design, and addressed the many shortcomings of commercially available braces. A case plan was developed from his design project report. It included a teaching objective to illustrate the resolution of a major design conflict. It was initially intended that the case be focused on need analysis and conceptual design.

It was also intended that this case be first used in $4^{\text {th }}$ year and in the Master of Engineering (MEng) Design Methods course, as an in-class group exercise to practice needs understanding and concept generation.

During the case development it became clear that the approach the student used was very well-structured. The report included sufficient background material on the medical condition and terminology, details of simple testing he performed, and an excellent summary on the fabrication of the actual brace by a certified orthotist. Based on this excellent summary, the teaching objectives were modified to highlight the use of the design method, in addition to the original objective of need analysis and concept generation to address a design conflict.

The case was drafted to include several modules, and these are summarized in Table IV.

TABLE IV

WCDE-00023 FoOt BRACE DESIGn CASE STRUCTURE [9]

\begin{tabular}{|c|c|c|}
\hline Module & Title & Comment \\
\hline 00 & Header & $\begin{array}{l}\text { Includes } \\
\text { - Case Title } \\
\text { - Authors } \\
\text { - Case number, number of pages } \\
\text { - Abstract } \\
\text { - Teaching/learning objective } \\
\text { - WCDE contact information }\end{array}$ \\
\hline 01 & Case & $\begin{array}{l}\text { Includes } \\
\text { - Introduction and opening } \\
\text { paragraph } \\
\text { - Description of design } \\
\text { situation/challenge/opportunity } \\
\text { - Description of the current state- } \\
\text { of-the-art } \\
\text { - Appendices describing medical } \\
\text { condition and terminology }\end{array}$ \\
\hline 02 & Needs Analysis & $\begin{array}{l}\text { Includes } \\
\text { - Design requirements list } \\
\text { - Criteria } \\
\text { - Appendix on Biomechanics of } \\
\text { Running }\end{array}$ \\
\hline 03 & Conceptual Design & $\begin{array}{l}\text { Includes } \\
\text { - Three feasible design concepts } \\
\text { - Decision matrix summarizing } \\
\text { merits of each concept against } \\
\text { defined design criteria } \\
\text { - Selected concept for further } \\
\text { development }\end{array}$ \\
\hline 04 & Detailed Design & $\begin{array}{l}\text { Includes } \\
\text { - Solid model of preliminary } \\
\text { - } \text { Resign } \\
\text { Review of preliminary design } \\
\text { against all design requirements } \\
\text { - Review of selected materials of } \\
\text { construction } \\
\text { - Solid model of detailed design } \\
\text { - Appendix summarizing testing } \\
\text { on existing brace designs }\end{array}$ \\
\hline
\end{tabular}


05

Prototype and Test

$\mathrm{TN}$
Includes

- Summary of fabrication process

- Summary of in-use evaluation

- Comparison of new brace with existing design

Includes

- Case introduction summary

- Summary of central design challenge

- Intended learning outcomes

- Recommended case use

- Request for feedback on use with contact information (continuous improvement initiative)

- Bibliography
In its most fundamental form, a design case is comprised of a description of the challenge, a feasible solution, and the Teaching Note. Appendices provide important background information on the field of study, theoretical concepts, supporting data and relevant terminology as required [11].

To support the document management, distribution and promotion of the case, a header module (00) has also been incorporated into the case structure. The header module is intended to summarize the case for educators looking for a case to suit a course need. The content contained within this module is consistent with that provided by other case publishing sources [12], and required by case clearing houses [13].

The central design challenge is described in the Case module (01). This is the essence of the case, and presents the issue to be resolved, the context, and direction for the students, usually in the form of one question.

The remaining modules of this case present solution modules $(02,03,04,05)$. These can be used in a so-called interrupted fashion, as the Teaching Note describes. Sequencing the delivery of each module, and fostering individual reflection and group interaction promotes engaging learning.

\section{DISCUSSION}

We have found that the case development process outlined above can be used successfully to convert either student work term reports or $4^{\text {th }}$ year capstone design project reports into useful design cases. Both are good sources of educational design material, with the student work term reports tending to emphasize analysis over synthesis, and the $4^{\text {th }}$ year capstone design reports focusing on synthesis over analysis.

We have a number of recommendations to complement the preceding formalized process that we hope will facilitate:

- new case developer training,

- student and instructor appreciation of cases, and

- engineering design training using the case method.

We offer the following lessons-learned from our initial experiences.

\section{LESSONS-LEARNED}

\section{A. Understand the Case Method}

It is important that the case developer and instructor really appreciate what the case method is all about. While we talk about developing and releasing cases, the ultimate goal is to facilitate the case method of discussion and questioning, in group and class formats.

There are a number of very good training courses on case writing and teaching, and we recommend instructors planning to use this type of teaching consider taking these prior to using them in class.

We recommend that instructors talk to other engineering or business professors who use cases on a regular basis for tips on the finer points of converting a lesson plan from lecture to lecture and case method format, and on facilitating rather than lecturing. University teaching resources can typically offer this support.

Finally engineering students tend not to like to discuss much in a lecture style setting. The use of cases may very well require a culture shift in addition to learning to learn with cases. This should be considered, and it is possible to address using a simple case as a warm-up.

\section{B. Sell Benefits of Report Conversion to Students}

Most students are also not cognizant of this new method of learning. This makes selling the use of their work term and design reports even more challenging, but feasible.

It is important to ensure students appreciate that their experiences will enrich the engineering curriculum. Some are concerned that this will require additional workload that they cannot afford to invest in. It is therefore important for case developers to help students understand that their involvement will be in a review capacity.

It is also important to communicate that they will receive acknowledgment through authorship and promotional benefit for their work, and that they retain all intellectual property rights to their work report.

We have learned engaging the student early facilitates effective and efficient case development.

\section{Conduct Interview with Student after Case Plan Complete}

We have found it very helpful to conduct a short interview with the student after they have read the case plan. A face to face meeting is useful in obtaining additional implicit information regarding their work, and allows the student to ask questions regarding the case method, and the copyright agreement and release process. It is also an opportunity to determine whether the student would be willing to act as a visiting guest during case delivery.

\section{Conduct Instructor Meeting Regarding Case Plan}

Having early adopters is crucial when introducing any new program. Faculty tends to be independent, and perhaps skeptical about making significant changes to the way in which they deliver their courses.

Our Departmental Design Champions have been wonderful in facilitating this awareness among faculty, but we have found it important to meet with faculty who may have a need 
for one of our cases, and with teaching note in hand, discuss with them the benefits.

The teaching note is a crucial tool here. It demonstrates that the case developer has thought out the learning objectives, and an implementation plan that can be reviewed. Assistance from the university teaching group, if available, can also be helpful in facilitating adoption.

While it is recognized that a specific course could benefit from the case method, a successful implementation requires a willing instructor, and therefore working with early adopters is best.

\section{E. Ensure Provisional Release is Obtained from Company and Lead Instructor}

The purpose of having a provisional release milestone in the process is to obtain agreement from all stakeholders in order to minimize investment risk and work. Writing a case only to find out after the fact that the student, instructor and/or company are unwilling to have it published is not productive.

A well-written case plan can mitigate against this risk. The key elements are including a well considered preliminary teaching note with intended learning outcomes, and including copies of the copyright license agreement and the case release form for student and company. Getting good adherence to the recommended time plan is sometimes difficult, but not impossible. Getting the proper company contact liaison, and communicating on a regular basis are good strategies for effective development.

\section{F. Develop Well-Considered Teaching Notes with Case Plan}

The development of a complete and well considered Teaching Note cannot be over-emphasized. It assists in effective and efficient case development. Being explicit about learning outcomes, especially those that target the three (3) highest levels of Bloom's Taxonomy of Educational Objectives;

- Analysis - breaking things down and modeling

- Synthesis - design and create, and

- Evaluation - deciding among alternatives and justifying,

are best for design cases [14].

Recognize also that these teaching notes may be tailored by each instructor depending on their specific course needs.

Finally we include a request to provide feedback on the case and the Teaching Notes, along with contact information.

\section{G. Peer Review, Release and Distribution}

The process of reviewing, releasing and distributing cases is important as it ensures that quality and consistency is developed and maintained. We have found that multiple peer reviews are required, and that this considerable effort is a worthwhile investment. Review is required for technical content, adherence to case structure and format, and finally for editorial accuracy and consistency.

Cases, as with any product, require management through a product life cycle, including retirement from distribution. It is obviously important to restrict the distribution of Teaching Notes to instructors only.

We have limited experience with hardware exhibits, but this is an area that has interesting potential for failure analysis, reverse engineering and re-design cases.

\section{CONCLUSION AND RECOMMENDATIONS}

Engineering design cases from work term reports and students' $4^{\text {th }}$ year capstone projects have been successfully developed using the case development process outlined above. Lessons learned have been captured and complement the formalized process.

The use of work term reports and student design project reports as sustainable sources of good case material seems promising.

This early experience also highlights the importance of generating teaching notes with explicitly stated intended learning outcomes. This supports effective case development, and encourages more faculty to consider adopting the case method.

Our early experience suggests that cases can be reliably generated using the process and lessons-learned experience described above.

\section{REFERENCES}

[1] C.I. Gragg, 'Because Wisdom Can't Be Told', Harvard Business School Publishing: Cambridge MA, HBR Case No. 9-451-005, 1982 (1940).

[2] R.R. Hake, 'Interactive-Engagement Versus Traditional Methods: A Six Thousand-Student Survey of Mechanics Test Data for Introductory Physics Courses', American Journal of Physics, 66(1), January 1998.

[3] D.J. Kulonda, 'Case Learning Methodology in Operations Engineering', Journal of Engineering Education, July 2001.

[4] O.G. Nespoli, A. Hagedorn, C. Campbell and S. Lambert, 'A Comparison of Business Case and Engineering Design Case Structures', Proceedings of the Canadian Design Engineering Network Conference (CDEN), 2008.

[5] W.M. Evan and M. Manion, Minding the Machines: Preventing Technological Disasters, Prentice-Hall, 2002.

[6] J.E. Davidson and R.J. Sternberg, The Psychology of Problem Solving, Cambridge University Press: Cambridge, UK, 2003.

[7] M.R. Leenders, L.A. Maufette-Leenders and J.A. Erskine, Writing Cases, $4^{\text {th }}$ Ed., IVEY Publishing: London, Ontario, Canada, 2001.

[8] S.R.L. Lancaster-Laroque, "Use of Magnets to Provide Resilience", US Patent Application Number 11/448,852, June 8, 2006.

[9] D. Bishop and O. Nespoli, 'Foot Brace Design for Long Distance Running', WCDE Case No. WCDE-00023, Waterloo Cases In Design Engineering: Waterloo, Ontario, Canada, 2008.

[10] D. Bishop, Design of a Foot Brace for Long Distance Running, ME481 Design Project Report, Department of Mechanical and Mechatronics Engineering, University of Waterloo, December 2007.

[11] S. Lambert, 'Elora Home Heating Retrofit', WCDE Case No. WCDE00022, Waterloo Cases in Design Engineering (WCDE): Waterloo, Ontario Canada, 2007.

[12] Teaching Materials Newsletter, Harvard Business School Publishing, Spring 2008.

[13] European Case Clearing House (ECCH) [Online], Available http://www.ecch.com

[14] L.W. Anderson, D.R. Krathwhol, P.W. Airasian, K.A. Cruikshank, R.E. Mayer, P.R. Pintricj, J. Raths and M.C. Wittrock, Ed., A Taxonomy for Learning, Teaching and Assessing, Toronto: Longman, 2001. 